\title{
A case of ectopic parathyroid hormone production by a pulmonary neoplasm
}

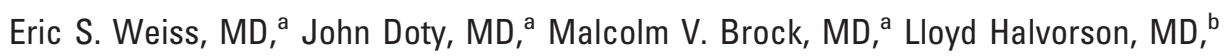
and Stephen C. Yang, MD, ${ }^{a}$ Baltimore and Fredrick, Md

$\mathrm{H}$ ypercalcemia is a well-recognized, albeit infrequent, complication of primary bronchogenic carcinoma. In contrast to neoplasms, which produce hypercalcemia by means of bony invasion with osteolysis, the cause of hypercalcemia in bronchogenic carcinoma has convincingly been demonstrated to be humoral in nature and almost exclusively associated with parathyroid hormone-related protein (PTH-rp). By stark contrast, only 3 cases of bronchogenic carcinoma associated with ectopic production of native parathyroid hormone (PTH) have been reported. ${ }^{1-3}$ Here we describe a rare case of a pulmonary neoplasm producing ectopic PTH. We further report the successful resection and restoration of normocalcemia in our patient. This unique case challenges conventional beliefs regarding the diagnosis and management of humoral hypercalcemia of malignancy.

\section{Clinical Summary}

A 71-year-old white woman presented to her community emergency department with lightheadedness, nausea, and difficulty with balance and was noted to have a serum calcium level of 18.8 $\mathrm{mg} / \mathrm{dL}$. Chest radiography revealed a right lung radiodensity, further characterized by chest computed tomography as a $2.4 \times$ 2.6- $\mathrm{cm}$ mass within the right midlung adjacent to the pleura. Transthoracic needle biopsy revealed non-small cell lung cancer favoring adenocarcinoma. She was started on calcitonin and palmidronate for her hypercalcemia and transferred to our tertiarycare facility for definitive treatment.

At our institution, her PTH level was measured at $288 \mathrm{pg} / \mathrm{mL}$ (normal range, 10-65 pg/mL). Her PTH-rp assay (Quest Diagnostics, San Juan Capistrano, Calif) was less than $0.2 \mathrm{pmol} / \mathrm{L}$ (normal, $<1.3 \mathrm{pmol} / \mathrm{L}$ ). Serum phosphate was low at $1.2 \mathrm{mg} / \mathrm{dL}$ (normal range, $2.7-4.5 \mathrm{mg} / \mathrm{dL}) ; 1,25(\mathrm{OH})$ vitamin $\mathrm{D}$ level was increased at $298 \mathrm{pg} / \mathrm{mL}$ (normal range, 15-60 pg/mL); and $25(\mathrm{OH})$ vitamin D level was within normal limits at $25 \mathrm{ng} / \mathrm{mL}$ (normal range, 9-52 $\mathrm{ng} / \mathrm{mL})$.

Technitium-99 sestamibi radionucleotide scanning revealed a focus of increased activity in the right midchest corresponding to

From the Department of Surgery, The Johns Hopkins Medical Institu-

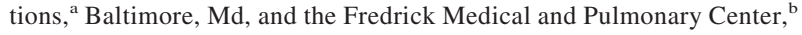
Fredrick, Md.

Received for publication Nov 11, 2005; accepted for publication Dec 9, 2005.

Address for reprints: Eric S. Weiss, MD, Department of Surgery, The Johns Hopkins Hospital, The Johns Hopkins Medical Institutions, PO Box 110 Tower, Baltimore, MD 21287 (E-mail: eweiss3@jhmi.edu).

J Thorac Cardiovasc Surg 2006;131:923-4

$0022-5223 / \$ 32.00$

Copyright (C) 2006 by The American Association for Thoracic Surgery doi:10.1016/j.jtcvs.2005.12.020 the lung mass (Figure 1) and a positron emission tomography scan demonstrated no metastatic disease (Figure 2). The patient was thus taken to the operating room, where an uncomplicated right upper lobectomy was performed to remove

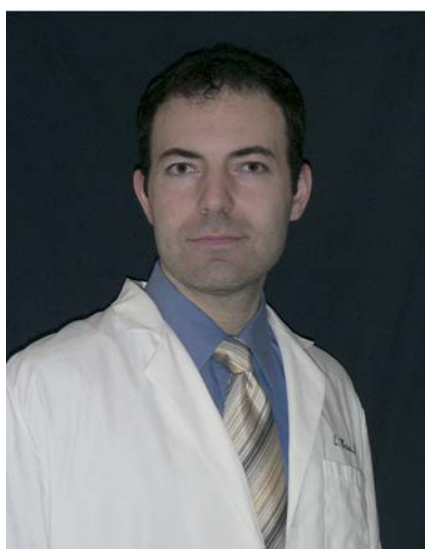

Dr E. Weiss the mass.

Final pathology revealed a T2 N0 M0, 3.5-cm-margin, negative, moderately differentiated adenocarcinoma of the right upper lobe. Serum PTH level drawn 1 day postoperatively decreased to $26 \mathrm{pg} / \mathrm{mL}$, and the patient's serum calcium level stabilized at 9.7 $\mathrm{mg} / \mathrm{dL}$. The patient returned to her preoperative state and has no evidence of recurrence or hypercalcemia 24 months after resection.

\section{Discussion}

Humoral hypercalcemia of malignancy is defined as hypercalcemia induced by ectopic production of hormonal factors by neoplastic cells. The syndrome was proposed by Fuller Albright in 1941. ${ }^{4}$ In Albright's description of a 51-year-old man with renal carcinoma and hypercalcemia, he speculated that the coexistence

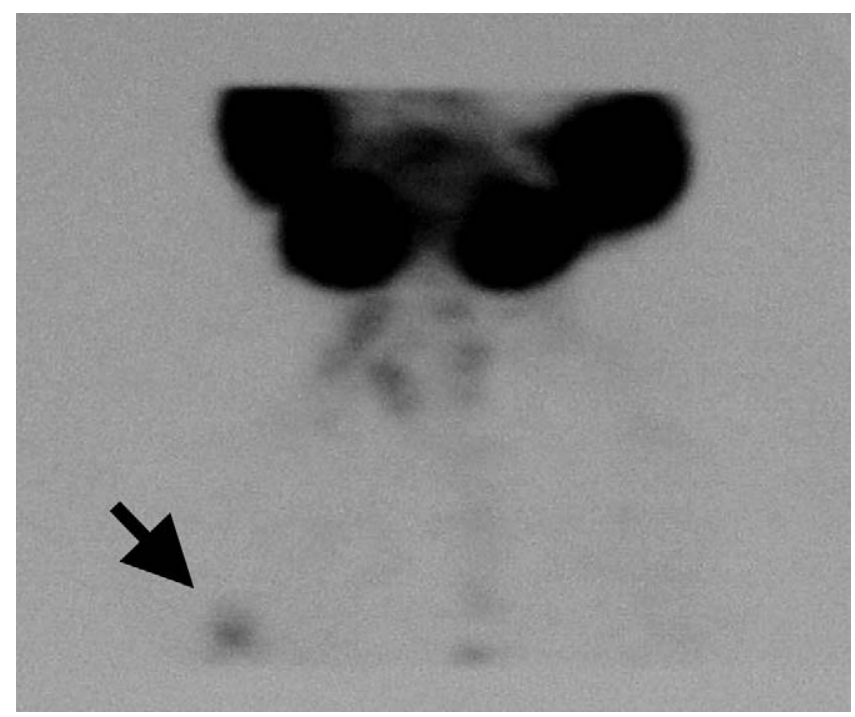

Figure 1. Technitium-99 sestamibi radionucleotide scan demonstrating a small focus of increased activity in the posterior portion of the right midchest corresponding with the pulmonary lesion (arrow). Radiotracer uptake is also present in $\mathbf{3}$ foci of the neck. The multiplanar spectrum imaging of the neck and upper chest seen here was obtained by using intravenous injection of technetium-99M sestamibi cardiolite. 


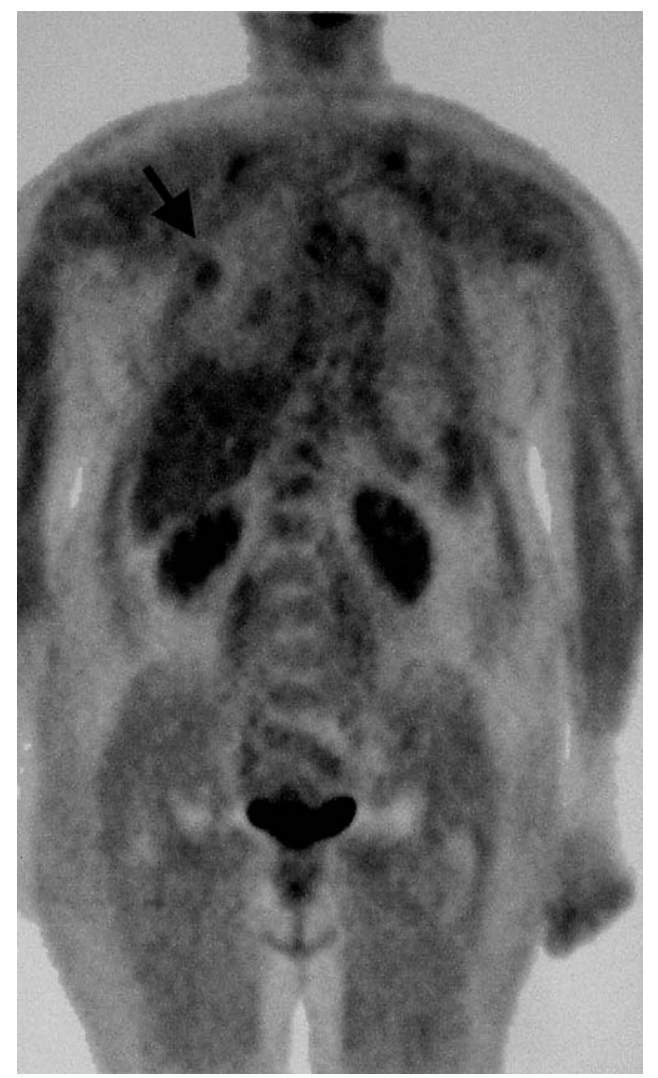

Figure 2. Positron emission tomographic scan demonstrating radiotracer uptake within the right middle lung (arrow). No metastatic foci are observed.

of hypophosphatemia was due to ectopic production of PTH by the tumor. Since then, humoral hypercalcemia of malignancy has become a well-recognized cause of tumor-induced hypercalcemia that is prevalent in pulmonary neoplasms. Although Albright was correct in suggesting that a humoral factor could account for hypercalcemia, most contemporary studies have identified parathyroid-related protein to be the factor chiefly responsible for hypercalcemia of malignancy.
It is quite rare, in fact, to find a primary tumor that generates a hypercalcemic state through the ectopic production of native PTH. Our own review of the literature identified 8 such cases. These included 3 primary bronchogenic tumors ( 1 squamous cell and 2 small cell), ${ }^{1-3}$ an ovarian tumor, a thymoma, a neuroectodermal tumor, a thyroid adenocarcinoma, and a hepatocellular carcinoma. ${ }^{5}$ Consistent with the physiologic role of PTH, these patients generally present with increased serum calcium levels, low phosphorus levels, and high levels of 1,25 $(\mathrm{OH})$ vitamin $\mathrm{D}$.

The clinical, radiographic, and laboratory data presented here support a ninth case of ectopic PTH secretion by a malignant neoplasm. The patient presented with an increased serum calcium level. Increased levels of 1,25 (OH) vitamin D; decreased levels of $25(\mathrm{OH})$ vitamin $\mathrm{D}$; and low phosphorous levels raised the suspicion that PTH and not PTH-rp was responsible for the hypercalcemia. This was verified by means of laboratory analysis demonstrating low levels of PTH-rp and increased levels of native PTH. A neoplastic cause for the above findings was supported by the substantial radiotracer uptake on sestamibi scanning favoring a high level of metabolic activity in the mass (Figure 1). Perhaps the most convincing data supporting native PTH production by the mass was the dramatic reduction in PTH levels from $288 \mathrm{pg} / \mathrm{mL}$ to $24 \mathrm{pg} / \mathrm{mL}$ after surgical resection of the specimen.

Beyond reporting unusual pathology, the above case illustrates how routine diagnostic workup of a common problem (hypercalcemia) can lead to unexpected results. One cannot assume that hypercalcemia with increased PTH levels is parathyroid in nature without proper investigation for potentially treatable malignant neoplasms producing paraneoplastic syndromes.

\section{References}

1. Nielson PK, Rasmussen AK, Rasmussen UF, et al. Ectopic production of intact parathyroid hormone by a squamous cell lung carcinoma in vivo and in vitro. J Clin Endocrinol Metab. 1996;81:3793-6.

2. Schmelzer HJ, Hesch RD, Mayer H. Parathyroid hormone and PTH mRNA in a human small cell lung cancer. Recent Results Cancer Res. 1985;99:88-93.

3. Yoshimoto K, Yamasaki R, Sakai H, et al. Ectopic production of parathyroid hormone by small cell lung cancer in a patient with hypercalcemia. J Clin Endocrinol Metab. 1989;66:976-81.

4. Albright F. Case records of the Massachusetts General Hospital case 27461. N Engl J Med. 1941;225:789-91.

5. Strewler GJ, Budayr AA, Clark OL, et al. Production of parathyroid hormone by a malignant non parathyroid tumor in a hypercalcemic patient. J Clin Endocrinol Metab. 1993;76:1373-5.

\section{Targeted}

The Journal of Thoracic and Cardiovascular Surgery gives you two tables of contents.

The condensed table of contents tells you at a glance what topics and authors are presented each month. The expanded table of contents gives you a brief abstract of each article. You select only those articles of most interest to you for further reading. 